\title{
Anaesthetic Management of a Case of Partial anomalous pulmonary venous circulation For Drainage of Brain Abscess : A Case Report
}

\author{
Dr Sukhen N Shetty ${ }^{1,}$ Dr Padmanabha $\mathrm{S}^{2,} \quad$ Dr Vinay Rasquinha ${ }^{3}$ \\ 1. Post graduate $3^{\text {rd }}$ year, Department of anaesthesiology, Yenepoya medical college and hospital, Deralakatte, \\ Mangalore. \\ 2. Professor and head of department, Department of anaesthesiology, Yenepoya medical college and hospital, \\ Deralakatte, Mangalore. \\ 3. Asst professor, Department of anaesthesiology, Yenepoya medical college and hospital, Deralakatte,
} Mangalore.

\begin{abstract}
Partial anamolous pulmonary venous circulation is a cyanotic congenital heart disease and is responsible for as many as $0.6 \%$ of all cases of congenital heart diseases of which the incidence in adulthood without correction is extremely rare(0.007\%). Complications like recurrent brain abscess always remain a risk. Incidental finding such as dextrocardia with ketonuria and being exposed to endosulphan makes our case much more complicated. We are hereby reporting the anaesthetic management of such a case with good outcome.

Keywords: Partial anamolous pulmonary venous circulation, Recurrent Brain Abscess, Dextrocardia, Ketonuria, Endosulphan, General Anaesthesia .
\end{abstract}

\section{Case report:}

A 30 year old Male patient, weighing 55kg from Kasaragod, presented to department of neurosurgery, Yenepoya medical college and hospital, Deralakatte, Mangalore with Fever since 10 days and altered sensorium since 1 day and an episode of vomiting. Patient party gave a history of known case of congenital heart disease (reports not available), old operated case of cerebral abscess (20 yrs back), right side hemiplegia (old history), known alcoholic (consumes alcohol every day for last 4 years), suspected ENDOSULPHAN exposure. In the hospital, the patient was evaluated and echocardiography revealed a ejection fraction $-60 \%$, moderate pulmonary artery hypertension, (PAP) $-37 \mathrm{mmHg}$, sclerotic aortic valve, small size ASD, PAPVC, right ventricular hypertrophy. ECG showed right axis deviation with right ventricular hypertrophy with a $\mathrm{qR}$ pattern in the right chest leads, Regularly irregular rhythm, ventricular ectopics occasionally. X-ray chest was suggestive of DEXTROCARDIA with oligemic lung fields. MRI scan ${ }^{(\text {fig } 1,2)}$ of the brain revealed multiple well defined thin rim enhancing lesions in the left fronto-temporal regions with surrounding peri-lesional edema and mass effect suggestive of cerebral abscess measuring $41 * 39 * 37 \mathrm{~mm}$, ventriculitis, choroid plexitis with leptomeningeal enhancement, repeat MRI scan revealed increase in size and midline shift

Biochemical investigations were normal on previous day (PCV 36.8\%), next day prior to taking up the case the haematocrit was $53.6 \%$ (hb -21.6gm\%). Urine sample revealed URINE KETONE BODIES: +++. Coagulation profile was within normal limits. On examination, patient was unconscious, not responding and ill looking, dehydrated. Pulse was 76 per minute and the blood pressure 120/70 $\mathrm{mmHg}$. Initially central cyanosis later peripheral cyanosis and Grade 3 clubbing ${ }^{(\mathrm{fig} 3,4)}$ of both upper and lower limbs was present. Examination of cardiovascular system revealed parasternal heave with a loud p2 and examination of respiratory system revealed bilateral fine crepitations heard . central nervous system examination revealed reflexes: on right side abolished, on left side - brisk knee jerk , plantar flexion. Examination of Pupils revealed Right side - reacting to light and Left side - dilated and non reactive.

In presence of an infective focus and in view of the urgent nature of surgery the patient was posted for burr hole with drainage of abscess under general anaesthesia. He was put on antibiotics, anticonvulsants and anti-oedema therapy. Preoperative arterial blood gas analysis revealed desaturation with a Sao2 of $80 \%$ and Pao2 of $48 \mathrm{mmHg}$. The case was accepted for surgery under ASA physical status ' $\mathrm{V}$ 'and a consent was obtained.

In the operating room, OT temperature was fixed at $22^{\circ} \mathrm{c}$, an intravenous line was established with $18 \mathrm{G}$ medicut. All intravenous tubing's, free of air bubble, epidural filters were used and the patient was connected to Philips monitor for monitoring of ECG, NIBP and SpO2. A prophylactic dose of antibiotic, Ceftriaxone $1 \mathrm{gm}$ and was given to provide prophylaxis against infective endocarditis. The patient was premedicated with glycopyrollate $0.2 \mathrm{mg}$ and after preoxygenation for 3 minutes, anaesthesia was induced with fentanyl $50 \mu \mathrm{g}$ and ketamine $50 \mathrm{mg}$ and thiopentone $75 \mathrm{mg}$ followed by rocuronium $50 \mathrm{mg}$ to facilitate 
endotracheal intubation. patient was intubated with 8.5 sized cuffed portex endotracheal tube. Anaesthesia was maintained with nitrous oxide in oxygen (50:50), isoflurane $(0.4-0.6 \%)$. Ventilation was controlled using a Bain's co-axial circuit to maintain slight hypocarbia. Propofol infusion was maintained at $100 \mu \mathrm{g} / \mathrm{kg} / \mathrm{min}$. The left radial artery was cannulated for direct arterial pressure monitoring and ABG analysis post operatively. A double lumen CVP catheter was inserted into the internal jugular vein. The bladder was catheterized to monitor the urine output.

Intraoperatively, the patient received eptoin $100 \mathrm{mg}$, dexamethasone $8 \mathrm{mg}$, mannitol 40gm and xylocard $60 \mathrm{mg}$ to lower the intracranial pressure and make the brain lax for the surgeon. Left fronto-temporal craniotomy was performed by the neurosurgeon and an encapsulated abscess cavity was drained and completely removed. The surgery lasted for about one and half hours and throughout the procedure, the patient remained stable with $\mathrm{SaO} 2$ ranging between $80-86 \%^{(\mathrm{fig} 5)}$. Normal saline and dextrose saline was used as maintenance fluid during surgery and about $200 \mathrm{ml}$ of blood lost was replaced. warmer was placed to avoid hypothermia

At the end of the surgery, the residual neuromuscular block was antagonized with neostigmine $2.5 \mathrm{mg}$ and glycopyrollate $0.4 \mathrm{mg}$ but patient was not extubated, Postoperatively, the patient was transferred to the surgical intensive care unit for overnight observation and after 48 hours was referred back to the neurosurgery ward with $\mathrm{O} 2$ saturation of $86 \%$ post extubation.

\section{Discussion:}

The amount of shunting of blood through ASD in partial anamolous pulmonary venous circulation(PAPVC) is determined by the ratio of the systemic vascular resistance (SVR) to pulmonary vascular resistance (PVR). As SVR is increased, right to left shunting decreases. To a smaller extent change in PVR will also have a reciprocal relationship on the pulmonary blood flow, although the primary factor governing pulmonary blood flow is the presence of infundibular or valvular pulmonary stenosis. The greatest perioperative concern is the development of cyanotic spells due to spasm of the hypertrophied pulmonary infundibulum. Both, tachycardia and increased myocardial contractility can lead to infundibular spasm. Another mechanism for such hypercyanotic episodes is decreased SVR increasing right to left shunting through VSD. Systemic blood pressures less than $60 \mathrm{mmHg}$ can trigger hypercyanotic episodes $\left[{ }^{2}\right]$. Management of anaesthesia for the patient with PAPVC requires a thorough understanding of the events and drugs that can alter the magnitude of right to left shunt which itself alters the pharmacokinetics of both inhaled and injected drugs $\left[{ }^{3}\right]$.

An anaesthesiologist's concern for a case of PAPVC with brain abscess include:

- Hypoxia

- Coagulopathies

- Lax brain

Hypoxia leads to hyperviscosity of blood and coagulation abnormality $\left[{ }^{4}\right]$. A haematocrit above $65 \%$ requires phlebotomy. If coagulation abnormalities are present, use of NSAID are avoided and platelet concentrates should be available perioperatively. In our patient the PCV was 53.6\% and did not have deranged coagulation profile.

Major goals of anaesthesia in PAPVC are to maintain systemic vascular resistance, minimize pulmonary vascular resistance and provide mild myocardial depression. Most of the patients have a dynamic right ventricular outflow obstruction which may be worsened by sympathetic stimulation during anaesthesia $\left.{ }^{5,6,7}\right]$. The optimal induction regimen for general anaesthesia in PAPVC should aim to improve arterial blood oxygen saturation (Sao2) and to maintain cardiovascular stability $\left[{ }^{8}\right]$. Both, intravenous and inhalational drug regimens have been used successfully for induction of anaesthesia in PAPVC to maintain systemic oxygenation and haemodynamic variables. Induction of anaesthesia itself using a variety of techniques have been shown to markedly increase arterial saturation. This induction related increase in arterial saturation probably results from higher systemic venous oxygen saturation due to high oxygen concentration plus decreased oxygen consumption with induction of anaesthesia and muscle paralysis $\left[{ }^{9},{ }^{10}\right]$.

Systemic venous blood with higher oxygen saturation is shunted in the systemic circulation, decreasing the degree of hypoxemia seen. However, systemic vasodilatation may occur during general anaesthesia and exacerbate the left to right shunting and intensify the resultant hypoxia. With the use of opiate technique, oxygen saturation levels are well maintained and may actually improve during induction, intubation and surgical stimulation even in cyanotic children or in adults $\left[{ }^{11}\right]$. We used a combination of fentanyl, thiopentone and ketamine in our case for induction of anaesthesia which actually improved arterial oxygenation and maintained it between $82-86 \%$ intraoperatively. Ketamine has been found to be the excellent induction agent in such cases as it improves the oxygenation by decreasing the right to left shunt as a result of increase in systemic vascular resistance $\left[{ }^{12}\right]$.

Lax brain is essential from surgical point of view. Hypocarbia and diuretic therapy are usually employed. Careful use of diuretic can avoid hypovolemia and maintain right ventricular output. Mannitol in a small dose is ideal as it reduces blood viscosity also. Frusemide induces hypovolemia to a greater extent $\left[{ }^{13}\right]$. 
We avoided hypovolemia by maintenance of intravascular volume. urine ketone bodies being present, we tackled it by giving a bolus of $10 \mathrm{ml} / \mathrm{kg}$ bd wt $0.9 \%$ saline.
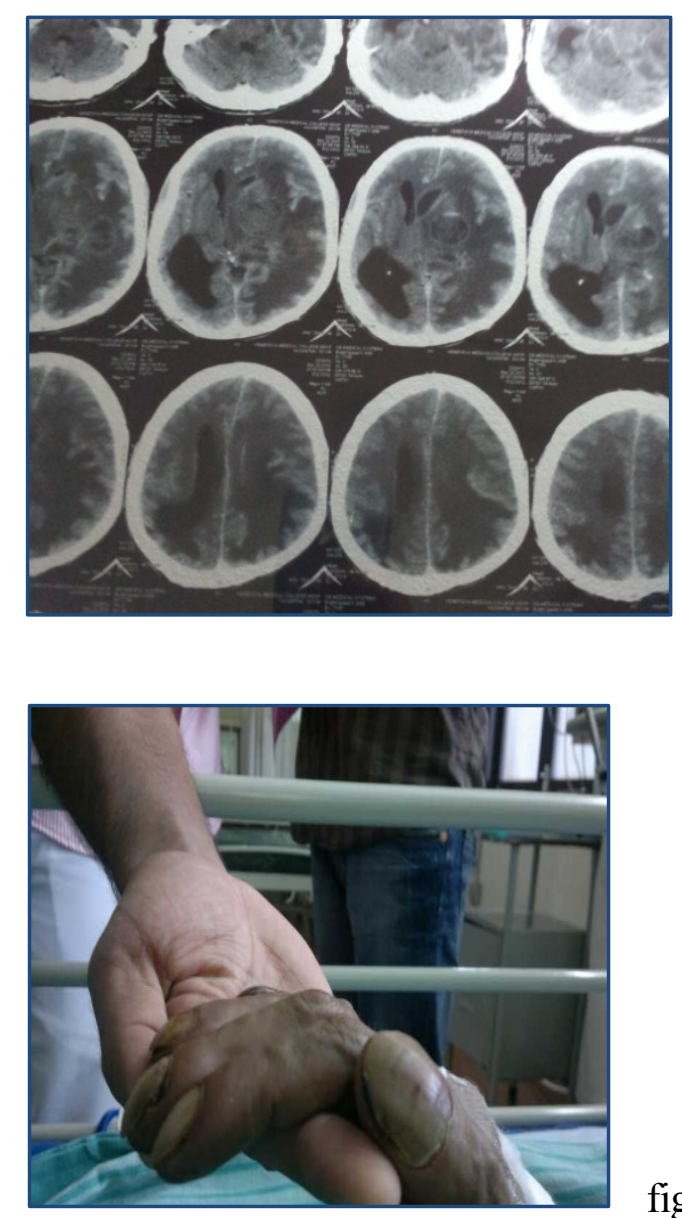

fig 1

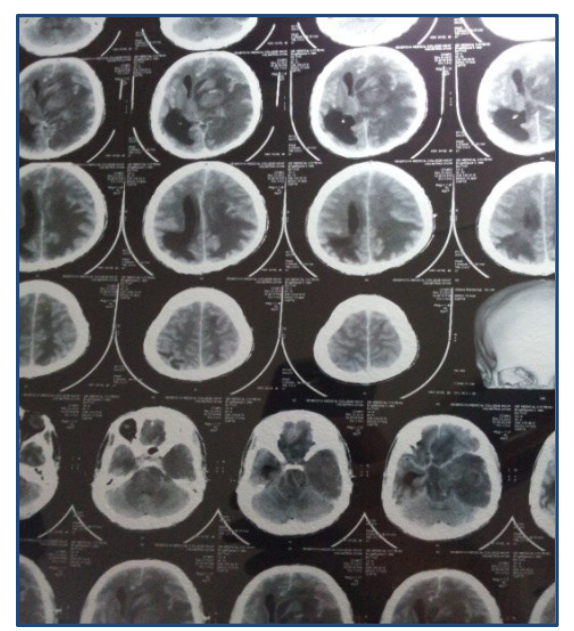

fig 2

fig 4

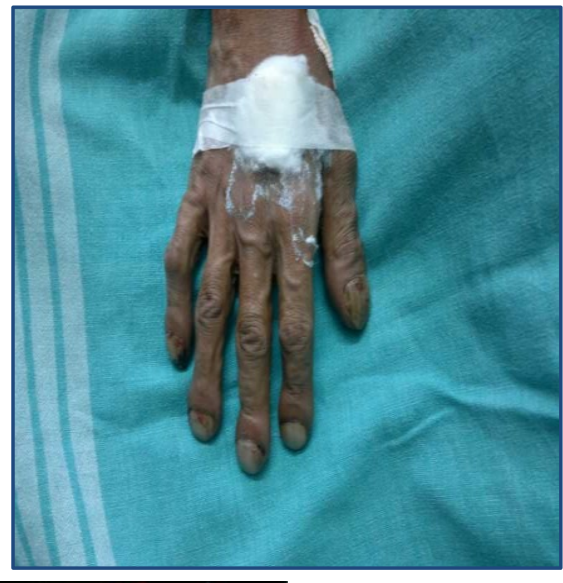

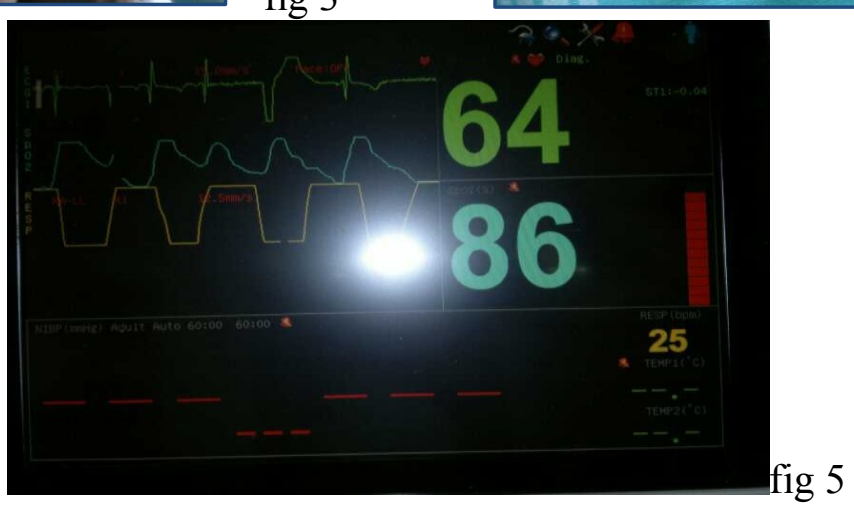

\section{Conclusion:}

In conclusion, aggressive perioperative management has resulted in good outcome of this patient. Understanding the sequence of events was also important in management of the patient:

Recurrent cerebral abscess most common etiology would be cyanotic congenital heart disease. Dextrocardia is a incidental finding. PAPVC in adults is rare, patient was apparently asymptomatic because of presence of ASD. Hypoxia lead to clubbing and cyanosis . hypoxia is also the reason for polycythemia. Urine ketone bodies is the result of dehydration/ alcoholism. Symptoms might have occurred due to reversal of shunt from right to left due to insult on right side of heart causing PAH.

\section{Correspondence to}

Dr Sukhen N Shetty, post graduate final year, Yenepoya medical college and hospital, Deralakatte, Mangalore, Karnataka, India. 


\section{References:}

[1]. Reed AP, Kaplan JA: Congenital heart disease, In Clinical case in anaesthesia, Churchill Living Stone Inc. 1989, P 119-128.

[2]. Oshita S, Uchimoto R, Aka H et al: Correlation between arterial blood pressure and oxygenation in the tetrology of Fallot. J. Cardiothorac Anaesth; 1998, 3: 597.

[3]. Beekamn RH, Rocchini AP; Transcatheter treatment of congenital heart disease. Cardiovascular Dis, $1989,32: 1$.

[4]. David Frankiville: Anaesthesia for non cardiac surgery in children and adults with congenital heart diseases. In paediatric cardiac anaesthesia, ed Carol L lake, 2nd edition. Appleton and Lange, pages 485-494.

[5]. A. T. Lovell et al; Anaesthetic implications of grown-up congenital heart disease, BJA Volume 93, Issue 1,Pp. $129-139$.

[6]. Ammash NM, Connolly HM, Abel MD, Warnes CA. Noncardiac surgery in Eisenmenger syndrome. J Am Coll Cardiol 1999; 33: 222-7

[7]. Babik B, Deak Z et al; Induction of anaesthesia in tetrology of Fallot- pitfalls to the maintenance of optimal oxygen saturation. Professional information, ASA Newsletter, 2000.

[8]. Laishley RS, Bossows FA et al: Effect of anaesthetic induction regimens on oxygen saturation in cyanotic congenital heart disease. Anaesthesiology, 1986, 65: 673-677.

[9]. Irish CL, Murkin JM, Cleland A et al: Neuromuscular blockade significantly decreases systemic oxygen consumption during hypothermic cardiopulmonary bypass. J. Cardiothoracic vas. Anaesth, 1991, 5: 132.

[10]. Lindhal SGE; Oxygen consumption and carbon dioxide elimination in infants and children during anaesthesia and surgery. British J. Anaesth, 1989, 62: 70 .

[11]. Beynem FM, Tarhan S: Anaesthesia for the surgical repair of congenital heart defects in children. In Tarhan S (ed): Cardiovas cular anaesthesia and postoperative care; 2nd Medical publishers Chicago, 1989, p 105.

[12]. Mark CR, John HT, Benjamin GC et al: Anaesthesia for treatment of congenital heart disease, a problem oriented approach, in principles and practice of Anaesthesiology. Vol 2: ed 1993, 1681-1718.

[13]. Marion DW, Letarte PB: Management of intracranial hypertension, Contemporary Neurosurgery, $1997,19: 3-4$. 